\title{
Importance of Epidemiology in Oral Health: Mexican Epidemiological System
}

\section{Orellana Centeno José Eduardo ${ }^{1 *}$, Valencia López Oscar David ${ }^{2}$ and Guerrero Sotelo Roxana Nayeli ${ }^{1}$}

${ }^{1}$ Public Health Research Institute, University of the Sierra Sur, Miahuatlán De Porfirio Díaz, Oaxaca, Mexico

${ }^{2}$ Municipal Studies Institute, University of the Sierra Sur, Miahuatlán De Porfirio Díaz, Oaxaca, Mexico

*Corresponding Author: Orellana Centeno José Eduardo, Public Health Research Institute, University of the Sierra Sur, Miahuatlán De Porfirio Díaz, Oaxaca, Mexico.

Received: October 14, 2019; Published: November 04, 2019

DOI: $10.31080 /$ ASDS.2019.03.0690

\begin{abstract}
Oral diseases are considered public health problems, cavities and periodontal diseases appear among the first ten causes of morbidity, affecting a large percentage of the population. An important tool to know the progression of these pathologies to be able to apply preventive measures and promotion, as well as to be able to develop public policies that strengthen the activity of the operational personnel and the health system. This paper aims to recognize the usefulness of developing a system of information exclusive to oral pathologies, as well as to recognize the advances that have been made to reduce the prevalence of oral diseases and the slopes of oral health.
\end{abstract}

Keywords: Epidemiology; Oral Health

Importance of epidemiology in oral health: Mexican epidem iological system

Chronic diseases are the main public health problems in most of the world. The pattern of becoming ill has changed throughout the world, mainly due to changing lifestyles, which include sugarrich diets, widespread use of tobacco and increased alcohol consumption. In addition to the socio-environmental determinants; Oral diseases are closely related to these lifestyles. Oral diseases are considered as one of the main public health problems due to their high prevalence and incidence in all regions of the world, and as in all diseases, the greatest burden is on vulnerable populations. The serious repercussions in terms of pain and suffering, impairment of function and the effect on the quality of life should also be considered. The treatment of oral diseases is extremely expensive and is not feasible in most low and middle income countries [1].

According to the World Health Organization, oral health is defined as the absence of chronic orofacial pain, mouth or throat cancer, ulcers at all oral levels, congenital defects such as cleft lip or cleft palate; As well as more common diseases in the mouth such as caries, periodontal disease and loss of dental organs and any other disease or disorder that affects the entire oral cavity [2].

These decades, of accelerated epidemiological and demographic changes have affected the health of Mexicans and implies adjustments that strengthen and favor the entire health system and be able to react dynamically according to the changes and each of the needs presented in the country, for example, the presence of infectious infectious diseases in entities with less progress in the human development index, being the first cause of morbidity in the southern states of the country; the presence of chronic degenerative diseases in the central and northern areas that affect development and growth in that geographical area of the country and as an emerging problem the violence that prevails in our country, which began in focused areas of the west and north of the country and that in This moment affects the entire national territory [3]. 
Various health programs, including oral health, have reoriented their actions to a new strategy for the integration of chronic disease prevention and health promotion in general. Chronic diseases (including oral) have common risk factors, most of which are preventable, such as dietary habits, excessive consumption of tobacco and alcohol or oral hygiene. Therefore, the Oral Health Program is not conceived alone, but as an element articulated to the Sectorial Health Program (PROSESA) that allows to reach the health and well-being of the population.

Epidemiological surveillance is a technical, scientific exercise and one of the main tools to know the behaviour of diseases among the population, in addition it allows us to identify the epidemic potential and risk factors that intervene in the aetiology of the pathologies and knowing it allows the health services prevent them, be able to attend them in the course of the disease health process or even eliminate them.

Epidemiological surveillance of oral disorders requires a continuous, systematic, timely and effective process to capture specific information about their occurrence and distribution, as well as the factors that condition them. This analysed information allows a better and more rational use of resources and techniques. The activity must be part of the usual functions of health services and its application facilitates the development of actions for the prevention and control of oral disorders [4].

\section{Phases of epidemiological surveillance}

The permanent phase, consisting of 405 monitoring units distributed in the 32 federal entities of the country. Its reduced scale allows to obtain the information with the required frequency (monthly, quarterly, semi-annual or annual). The results of the information obtained are articulable with those produced by routine systems, allowing a complementary interaction between them [5].

The sentinel sites operate with the functional instances of the National Health System, in which are provided dental care services to the population, from which you will get fast and timely information to guide the actions of health services.

The survey phase, where the design of the samples will be representative at the state level, will include rural and urban areas, will be executed with standardized criteria. Its execution will allow deepening the characteristics and behavior of oral disorders, as well as assessing the impact of prevention strategies on the population. The information will be obtained every three years, through questionnaires focused on oral health [6].

The special investigations phase will arise from the problems detected in the phases previous, that is, will allow to know the characteristics of specific oral problems in certain populations, with the purpose of establishing adequate control and prevention measures.

The model integrated by the three phases allows to cover different angles of the problem in a complementary way, reducing costs and efforts of health personnel.

The reason why a person attends the medical consultation, goes beyond the burden of morbidity that may be suffering. This phenomenon exists since a small part of people with symptoms of a condition, request specialized attention, that is, the use of services is determined by various factors in addition to the presence or absence of health problems.

In 1970 our country had 1890 dentists in public institutions that granted a total of 4, 111,509 dental consultations $(39.4 \%$ first time and $60.6 \%$ subsequent), this is 85 consultations per 1,000 inhabitants. In 1990 these amounted to 100 per 1,000 inhabitants and in 2008 the National Health System indicated that 15.27 million were granted, that is, 143 consultations per 1,000 habitants [7].

\section{Conclusions}

We must consider that having the figures and numbers that these epidemiological surveillance systems show are in order to obtain accurate information about the population's situation and that the State, to the extent, can adequately combat the health inequality that exists in our country, since in Mexico it is common to find the so-called Frohlich inequality paradox, where groups with greater health needs have greater social deprivation and receive less health care [8].

It should be considered from oral health policies, a better integration of oral health services to those of general care and assume oral health as a right, a social guarantee and a pillar for human development [9].

As well as guaranteeing to the population strategies of promotion, education for health and prevention at all levels of the disease [10]. 


\section{Financing}

None (Own resources).

\section{Conflict of Interest}

None.

\section{Contribution of Authorship}

Participation of all authors in the review and writing of the article.

\section{Bibliography}

1. Petersen PE and Lennon MA. "Effective use of fluorides for the prevention of dental caries in the 21st century: the WHO approach". Community Dentistry and Oral Epidemiology 32 (2004): 319-321.

2. Organización Mundial de Salud. Salud bucodental. Nota informative 318 (2007).

3. Juan Mercedes y Grupo de trabajo de la fundación mexicana para la salud., et al. "Universalidad de los servicios de salud en México”. Salud Pública de México 55 (2013): 1-64.

4. Secretaría de Salud. "Subsecretaría de Prevención y Promoción de la Salud'. Resultados del Sistema de Vigilancia Epidemiológica de Patologías Bucales (SIVEPAB) 2012. Centro Nacional de Programas Preventivos y Control de Enfermedades. México, Distrito Federal (2012).

5. Secretaria de Salud (2001) Programa de Salud Bucal. Encuesta Nacional de Caries Dental 2001. México, Distrito Federal: Secretaría de Salud, Centro Nacional de Vigilancia Epidemiológica y Control de Enfermedades, (2006).

6. Sistema de Vigilancia Epidemiológica de Patologías Bucales (SIVEPAB) (2011) Resultados del Sistema de Vigilancia Epidemiológica de Patologías Bucales SIVEPAB 2010, primera edición, noviembre del 2011, Secretaría de Salud/ Subsecretaría de Prevención y Promoción de la Salud, Centro Nacional de Programas Preventivos y Control de Enfermedades (2011).

7. Instituto Nacional de Estadística y Geografía (México). Anuario estadístico y geográfico por entidad federativa 2010". Instituto Nacional de Estadística y Geografía. México (2010).

8. Frohlich KL and Potvin L. "Trascending the known in public health practice: the inequality paradox: the population approach and vulnerable populations". American Journal of Public Health 98.2 (2008): 216-221.
9. Orellana-Centeno JE., et al. "Salud bucal como derecho humano desde la situación legal en México". Avan C. Salud Medicines 7.2 (2019): 52-56.

10. Griffin SO., et al. "Burden of oral disease among older adults and implications for public health priorities". American Journal of Public Health 102.3 (2012): 411-418.

\section{Volume 3 Issue 12 December 2019}

(C) All rights are reserved by Orellana Centeno José Eduardo., et al. 